\title{
Black and Blue
}

\author{
Diego Kauffmann-Guerrero ${ }^{\mathrm{a}}$ Kathrin Kahnert ${ }^{\mathrm{a}}$ Sebastian Pratschke ${ }^{c}$ \\ Matthias Angstwurm ${ }^{b}$ Amanda Tufman ${ }^{a}$ Rudolf Maria Huber ${ }^{a}$ \\ a Division of Respiratory Medicine and Thoracic Oncology, Department of Internal Medicine V, University of Munich \\ (LMU), Comprehensive Pneumology Center, Member of the German Center for Lung Research (DZL), \\ ${ }^{b}$ Department of Internal Medicine IV, University Hospital Ludwig-Maximilians University (LMU) of Munich, and \\ 'Department of General, Visceral, and Transplantation Surgery, Hospital of the LMU Munich, Munich, Germany
}

Emergency medical services were called to a 54-yearold man seen staggering in a park vomiting black fluid. $\mathrm{He}$ aspirated repeatedly, and his condition deteriorated. A medical history was not possible. During intubation in the intensive care unit, a physician whose skin came into brief contact with his vomit developed localized redness. The patient's oral mucosa and lips turned black. Bronchoscopy revealed blueish-black mucosa in the trachea and both main bronchi as well as black foamy secretions (Fig. 1).
A CT scan revealed a perforation of the upper gastrointestinal tract and free abdominal fluid. An explorative laparotomy showed black discoloration and necrosis of the stomach with gastric perforation and multiple areas of necrotic colon. The patient required high levels of catecholamine support, and broad empiric antibiotics were started. Two days later, a relaparotomy with gastrectomy was performed. After a further 4 days, the patient developed multiple intestinal perforations. Otorhinolaryngological examination also revealed extensive colliquative
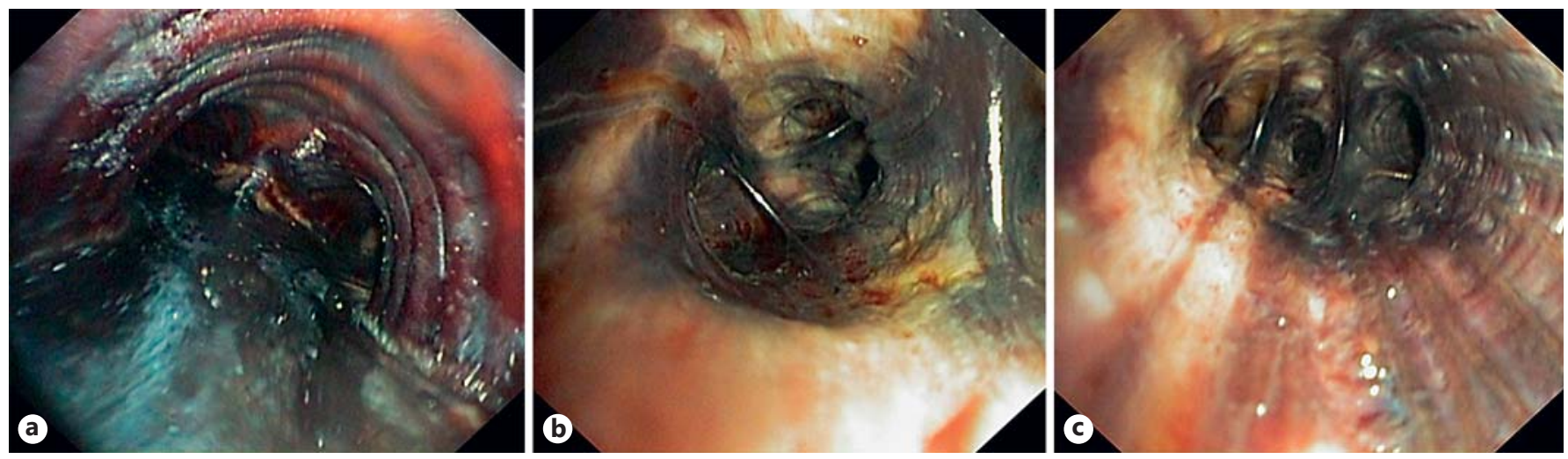

Fig. 1. View of the main carina (a) and of the left (b) and right (c) lower lung lobe segments. Diffuse black discoloration of the endobronchial mucosa without signs of acute bleeding.

\section{KARGER}

() 2017 S. Karger AG, Basel

E-Mail karger@karger.com

www.karger.com/res
Dr. med. Diego Kauffmann-Guerrero

Department of Internal Medicine V, University of Munich (LMU)

Ziemssenstrasse 1

DE-80336 Munich (Germany)

E-Mail Diego.KauffmannGuerrero@med.uni-muenchen.de 
necrosis. By day 7 , the extent of internal necrosis had made further interventions futile. Intensive care measures were discontinued, and the patient died on the same day.

Toxicological examination of urine, blood, and free abdominal fluid revealed ingestion of a strong base as the cause of the colliquative necrosis and gastrointestinal perforations. There are some reports in the literature, especially from gastrological endoscopies, which describe black discoloration of the mucosa after ingestion of acids or alkaline agents $[1,2]$. Experimental data showed that caustic ingestion leads to a coagulative necrosis with thrombosis of the underlying mucosal blood vessels, which may be responsible for the black color [3-5]. Acid or alkaline substances that can cause similar findings after ingestion are usually found in disinfectants used in home or laundry facilities or in batteries, e.g., sodium hydroxide, potassium hydroxide, hydrochloric acid, or sulfuric acid $[4,6]$.

At the time of initial presentation, we also discussed other potential causes of black discoloration of the oral and endobronchial mucosae, including ingestion/aspiration of heavy metals, arsenic, potassium permanganate, or extensive exposure to cigarette smoke.

\section{References}

1 Lee WC, Lee TH, Cho JH: White esophageal mucosa and black gastric mucosa: upper gastrointestinal injury due to hydrochloric acid ingestion. Clin Endosc 2014;47:119-120.

2 Poelman JR, Hausman RH, Hoitsma HF: Endoscopy in lye burns of oesophagus and stomach. Endoscopy 1977;9:172-177.

3 Fisher RA, Eckhauser ML, Radivoyevitch M: Acid ingestion in an experimental model. Surg Gynecol Obstet 1985;161:91-99.
4 Park KS: Evaluation and management of caustic injuries from ingestion of acid or alkaline substances. Clin Endosc 2014;47:301307.

5 Howell JM: Alkaline ingestions. Ann Emerg Med 1986;15:820-825.

6 Contini S, Scarpignato C: Caustic injury of the upper gastrointestinal tract: a comprehensive review. World J Gastroenterol 2013;19:39183930. 